\title{
nature
}

\section{Making collider endorsement count}

\section{There is broad backing for a US bid to build the International Linear Collider.}

$\Lambda$ multidisciplinary panel of senior scientists last week endorsed strong US participation in the construction of the International Linear Collider (ILC), the accelerator project that particle physicists see as their top priority. In a report from the National Academy of Sciences (see page 1094), the panel called on the US government to bid to host the ILC.

The Department of Energy and the National Science Foundation, the two agencies that support high-energy physics in the United States, should take the panel's advice and develop such a bid. Unlike previous high-energy physics projects, this one will be truly global from the start. Such international projects need strong backing at the most senior levels of government if they are to progress.

The arguments for building the ILChave been well rehearsed (see Nature 426,$105 ; 2003)$. The machine would mark a logical progression from the Large Hadron Collider (LHC), which is now under construction at CERN, the European particle-physics laboratory near Geneva, Switzerland. It would enable physicists to engage in the detailed study of particles, such as the Higgs boson, that they hope to find with the LHC. A US bid to host the ILC would confirm the nation's commitment to particle physics and lend valuable impetus to the collider project. Germany, Japan and CERN itself may also bid to host the project.

High-energy physics is an expensive business, and it is likely that, after the ILC, the basic approach of studying it by building everlarger particle accelerators will need to be revisited. However, the ILC will attain clearly defined scientific goals at a level of cost somewhere between $\$ 5$ billion and $\$ 10$ billion - that can be borne by a well-planned international effort.

The academy panel contains several eminent non-physicists, such as Harold Shapiro, an economist from Princeton University who chaired it, and biologist Harold Varmus, president of the Memorial Sloan-Kettering Cancer Center in New York and former director of the National Institutes of Health. Their endorsement of the project reflects a consensus within the wider scientific community that particle physics, although expensive and esoteric, is of fundamental importance and worthy of support.

The effort to translate that scientific consensus into political backing for the construction project is only just beginning. So far, those involved with the ILChave done a reasonably good job of maintaining the global nature of the project and ensuring that the physics community remains united behind it. There have been some exceptions to this pattern: the insistence of CERN, for example, that decisions about the siting of the ILC be delayed until an accelerator technology it is trying to develop is ready, strikes some in the community as unnecessary and self-serving.

Although physics from the LHC should feed into the design of the ILC, an international panel chaired by Barry Barish of the California Institute of Technology selected an accelerator technology for the design two years ago, and upwards of $\$ 100$ million has already been spent on preparatory research. It is time to start talking about sites.

\section{"The effort to translate the scientific consensus into political backing for the construction project is only just beginning."}

However, such a discussion requires an expression of willingness from candidate nations to host the facility, and probably to shoulder at least half of its construction costs. Two years ago, the Office of Science at the Department of Energy identified the ILC as its main medium-term priority. But as with ITER, its top priority, there has been no sign of any willingness from the White House to allocate extra funds for the project.

In the end, political backing for the deal is likely to come from friends of Fermilab, the laboratory near Chicago where it might be built. Fermilab has firmly hitched its wagon to the ILC (see Nature 435,$713 ; 2005$ ) and is looking to its supporters, such as House speaker Dennis Hastert (Republican, Illinois), to get the project on to the political agenda. Armed with this latest report, that task becomes a bit easier.

\section{Bioethics at the bench}

\section{Bioethicists should be close - but not too close - to the lab action.}

W hat are the rights of parents and fetuses when genetic tests reveal a $50 \%$ likelihood of a disabling illness by the time a child reaches adulthood? Should patients be required to give active consent if their health data are to be used in the future for unforeseeable biomedical research? How should different viewpoints on religion, philosophy and the natural and social sciences be brought to bear in setting regulations?
These are the sorts of questions that bioethicists deal with. Some researchers, however, pay little heed to bioethics, or regard it as a potential impediment to their work. Concerns about the relationship between bioethics and science are as old as the field itself.

Studies into the ethical, legal and social implications (ELSI) of the human genome project, funded mainly by the National Institutes of Health (NIH), were responsible for the rapid expansion of academic bioethics in the United States. But this diverse community has attracted criticism from researchers for being too remote from real science - and from public-interest groups for being too close to it. The latter want to know how it can present a convincing critique of genomics, given its reliance on $\mathrm{NIH}$ institutes and investigators.

"The professional field of bioethics has a great deal to say about 
many fascinating things, but people in this profession rarely say 'no," political scientist Langdon Winner of Rensselaer Polytechnic Institute in New York state told the House science committee in April 2003. "Indeed, there is a tendency for career-conscious social scientists and humanists to become a little too cosy with researchers in science and engineering, telling them exactly what they want to hear."

After the completion of the human genome project, the ELSI programme at the NIH evolved to direct significant support to four centres of excellence. The National Human Genome Research Institute, which provides most of the funding, says it hopes that these centres will each develop a sufficiently strong identity to support the growth of the next generation of ELSI researchers.

Several of these bioethics centres of excellence say they are trying to establish closer links with more laboratory researchers (see page 1104 ), and that their bioethicists will make themselves more readily available to provide rapid advice to faculty members. They see this as a way of fostering more ethical thinking in the design and execution of research, long before they would otherwise think of bioethics.

Researchers have to seek ethical advice willingly and then be prepared to act on it. There is no enforcement mechanism for bioethics

or sanctions; and, unlike Institutional Review Boards, bioethics advice rarely carries any weight in law. But that should not dissuade more ethicists from getting involved with the practical applications of their expertise.

Moreover, this kind of advice may turn out to serve a useful promotional function for bioethics itself. One part of this is simply to increase awareness of ethics; it is telling that half of the enquiries during the pilot phase of the first of these projects, at Stanford University in California, simply required lab researchers to be reminded of existing ethical guidelines. But much of the advice is provided in confi-

"Several of these bioethics centres of excellence say they are trying to establish closer links with more laboratory researchers." dence, raising issues of transparency in the event that research practices violate ethical norms.

Notwithstanding concerns about excessive cosiness with scientists, an academic bioethics community that is too aloof won't help science or ethics. As bioethicists strive to be heard beyond their own community, and for their advice to be valued, these models provide one useful way forwards.

\section{Machine readability}

\section{A publishing initiative seems ready to make text mining simpler.}

or many years Tim Berners-Lee, the inventor of the World Wide Web, has dreamed of machines being able to help humans use his creation. This would enable not only sophisticated search tools to hunt for words or phrases, but also for other engines to hunt for meanings and patterns. This 'semantic web' is being pieced together gradually. The latest step forward brings users of the scientific literature closer to that dream by enhancing computer access to the full text of the scientific literature.

Many scientists are used to the idea of data mining: the ability to plunder all the available databases to search not only for relevant nuggets, but also for unexpected combinations of data that reveal or at least hint at - relationships and mechanisms. They are not so used to the analogous function of mining texts.

But some researchers have made a start. Biologists, for example, have developed software that explores open 'text bases', especially the PubMed database. They scan many publications in order to discover relationships based on phrases or sentences that, when analysed in combination, cumulatively link one object (such as a disease) to another (such as a molecule). At the University of California, Berkeley, the BioText project is being used to explore apoptosis, for example (http://biotext.berkeley.edu). At the University of Illinois in Chicago, the Arrowsmith software explores the causes of disease (http://arrowsmith.psych.uic.edu/arrowsmith_uic/index.html). And at the European Bioinformatics Institute near Cambridge, UK, the EBIMed retrieval engine explores protein-protein interactions (http://www.ebi.ac.uk/Rebholz-srv/ebimed/index.jsp).

But publishers have yet to develop a standard annotation of their content that allows computers access to the full text. Earlier this month, the Nature Publishing Group launched a preliminary proposal for such a standard. The proposal is not a commercial product but rather a potential service for the community. It is open for comment and is not intended to provide a competitive advantage to us: on the contrary, it will only succeed if adopted by other publishers.

The proposal is the Open Text Mining Interface (OTMI), which was first presented at the Life Sciences Conference and Expo in Boston earlier this month. A description and examples can be found at http://blogs.nature.com/wp/nascent/2006/04/open_text_mining interface_1.html. The proposal would make coded text freely available to all. If all publishers were to adopt this or some similar standard, the entire literature would become accessible for mining.

How does this proposal relate to publishers' various business models? 'Author pays' publishers would be able to use this approach to machine readability and help users find their content more easily. 'Subscriber
"If all publishers were to adopt this or some similar standard, the entire literature would become accessible for mining." pays' publishers would follow the Nature Publishing Group in making this version of the full text freely explorable by machines but unreadable by humans. (Charging for machine access across diverse publishers' firewalls would effectively make machine text-mining impossible.) The OTMI approach to encryption is to jumble up sentences, retaining semantic relationships as far as possible.

Critics will point out that this limits the machine readability too; for example, some proximity searching becomes impossible. But the subscriber-pays model is strongly supported in the marketplace. OTMI represents a potential compromise between business needs and open access. Nature and its publishers welcome feedback about this initiative, which should be sent either to nature@nature.com or to the above-mentioned blog. 